Case Report

\title{
Amisulpride Augmentation for Clozapine-Refractory Positive Symptoms: Additional Benefit in Reducing Hypersialorrhea
}

\author{
Fabiani Bogorni, ${ }^{1}$ Frederico Fernandes Moreira, ${ }^{1}$ Eduardo Mylius Pimentel, ${ }^{1}$ \\ Géder Evandro Motta Grohs, ${ }^{1}$ and Alexandre Paim Diaz ${ }^{1,2}$ \\ ${ }^{1}$ Programa de Residência Médica em Psiquiatria do Instituto de Psiquiatria de Santa Catarina (IPQ/SC), \\ 88.123-300 São José, SC, Brazil \\ ${ }^{2}$ Centro de Neurociências Aplicadas, Universidade Federal de Santa Catarina, 88.040-970 Florianópolis, SC, Brazil \\ Correspondence should be addressed to Alexandre Paim Diaz; alexandrepaimdiaz@gmail.com
}

Received 12 January 2015; Revised 21 February 2015; Accepted 1 March 2015

Academic Editor: Toshiya Inada

Copyright (C) 2015 Fabiani Bogorni et al. This is an open access article distributed under the Creative Commons Attribution License, which permits unrestricted use, distribution, and reproduction in any medium, provided the original work is properly cited.

One-third to half of patients taking clozapine suffer from refractory symptoms despite adequate treatment. Among other adverse effects, clozapine-induced hypersalivation $(\mathrm{CIH})$ occurs in approximately half of all patients. This is a case of a 30 -year-old male with refractory schizophrenia; in this patient, the remission of residual positive symptoms, as well as the reduction of $\mathrm{CIH}$, was achieved by treatment with clozapine augmented with amisulpride.

\section{Introduction}

Approximately $30 \%$ of patients diagnosed with schizophrenia are resistant to antipsychotics and are candidates for treatment with clozapine. Still, one-third to half of patients taking clozapine suffer from refractory symptoms despite adequate treatment $[1,2]$. Among other adverse effects, clozapineinduced hypersalivation $(\mathrm{CIH})$ occurs in approximately half of all patients $[3,4]$. We report the case of a 30 -year-old male with refractory schizophrenia; in this patient, the remission of residual positive symptoms, as well as the reduction of $\mathrm{CIH}$, was achieved by treatment with clozapine augmented with amisulpride.

\section{Case Report}

The patient was admitted to the inpatient unit of a tertiary psychiatric hospital with command auditory hallucinations, persecutory delusions, and suicide ideation, despite regularly taking $900 \mathrm{mg} /$ day clozapine and $30 \mathrm{mg} /$ day aripiprazole. This patient was also being given $1 \mathrm{~g}$ /day valproic acid and $1.5 \mathrm{mg}$ /day haloperidol twice daily; haloperidol was initiated at admission, in the emergency room. His first psychotic episode occurred at the age of 21, when he set himself on fire motivated by auditory hallucinations.

This patient was evaluated on September 25, 2014, and was found to have moderate positive symptoms using the Brief Psychiatric Rating Scale (BPRS; total score: 4; suspiciousness: 3; hallucinations: 0 ; and unusual thought content: 1); mild suicidal ideation according to Hamilton Depression Rating Scale (HDRS; 1 point for the third item, "feels life is not worth living"); and massive salivation using the Nocturnal Hypersalivation Rating Scale (NHRS; score: 4; "very severeawakening due to hypersalivation"). The patient suffered from hypersalivation before treatment with aripiprazole was initiated, and treatment with aripiprazole, as well as the addition of haloperidol from the admission, did not worsen the $\mathrm{CIH}$ according to the patient, confirmed by information from his caregiver. Aripiprazole was gradually discontinued, and up to $50 \mathrm{mg} /$ day amisulpride was added. Four weeks later, his score on the NHRS was 1 ("mild-signs of saliva on pillow"), and he had no positive symptoms according to the BPRS and no suicidal ideation. Ten weeks after discharge, his positive symptoms remained in remission, and he continued to have no suicide ideation. However, at this third assessment, sialorrhea was found to have worsened, although it was less severe than it had been at the first evaluation. 


\section{Discussion}

The efficacy of clozapine augmentation with amisulpride has been demonstrated in a single-blind, randomized study [5]. The efficacy of amisulpride may be related to its unique ability to blockade $\mathrm{D}_{2} / \mathrm{D}_{3}$ receptors, especially in limbic regions, rather than striatal structures [6]. Moreover, the $\mathrm{D}_{2}$ partial agonism of amisulpride helps to explain both its antipsychotic property and fewer incidences of extrapyramidal symptoms [7].

Few studies have reported the use of amisulpride for the control of CIH. Kreinin et al. (2006) found a considerable reduction in $\mathrm{CIH}$ following amisulpride augmentation, in addition to significant improvements in negative symptoms [8]. Different from clozapine, amisulpride does not display significant affinity for muscarinic receptors, whose activity probably is the main mechanism of excessive salivation [7, 9]. However, the antisalivation mechanisms of the interaction between clozapine and amisulpride remain unknown, and experimental studies have failed to demonstrate any inhibitory influence of amisulpride on the flow of saliva [10]. The positive association between higher doses of clozapine and intensity of the muscarinic activity may collaborate to the incidence of $\mathrm{CIH}$ in patients with schizophrenia and refractory symptoms [7].

We cannot discard the possibility of an eventual change in the pattern of adherence as the reason for the fluctuations in the severity of excessive salivation after the inpatient treatment. Still, as the prescription was the same since the discharge from the hospital, it is unlikely that the fluctuation in the severity of excessive salivation during the followup is due to changes in the pharmacological profile of the treatment.

Further studies are needed to clarify the mechanisms underlying both of these actions of this drug. To our knowledge, this is the first case report describing the benefits of clozapine augmentation with amisulpride for reducing both positive symptoms and $\mathrm{CIH}$.

\section{Consent}

Written informed consent was obtained from the patient and his caregiver for publication of this report. A copy of the consent is available for review.

\section{Conflict of Interests}

The authors declare that there is no conflict of interests regarding the publication of this case report.

\section{Authors' Contribution}

All authors contributed equally in the preparation and writing of this case report.

\section{References}

[1] N. B. Pai, M. Laidlaw, and S.-L. Vella, "Augmentation of clozapine with another pharmacological agent: treatment for refractory schizophrenia in the 'real world"' Acta Psychiatrica Scandinavica, vol. 126, no. 1, pp. 40-46, 2012.

[2] J. M. Kane, "Clinical efficacy of clozapine in treatmentrefractory schizophrenia: an overview," British Journal of Psychiatry, vol. 160, no. 17, pp. 41-45, 1992.

[3] M. Ozbilen, C. E. Adams, and J. Marley, "Anticholinergic effects of oral antipsychotic drugs of typicals versus atypicals over medium- and long-term: systematic review and meta-analysis," Current Medicinal Chemistry, vol. 19, no. 30, pp. 5214-5218, 2012.

[4] L. Davydov and S. R. Botts, "Clozapine-induced hypersalivation," Annals of Pharmacotherapy, vol. 34, no. 5, pp. 662-665, 2000.

[5] Y. Genç, E. Taner, and S. Candansayar, "Comparison of clozapine-amisulpride and clozapine-quetiapine combinations for patients with schizophrenia who are partially responsive to clozapine: a single-blind randomized study," Advances in Therapy, vol. 24, no. 1, pp. 1-13, 2007.

[6] S. Porcelli, A. Serretti, and O. Bianchini, "Clozapine augmentation with amisulpride," Journal of Psychiatry \& Neuroscience, vol. 39, no. 6, pp. E38-E39, 2014.

[7] S. M. Stahl, Stahl's Essential Psychopharmacology. Neuroscientific Basis and Practical Applications, edited by S. M. Stahl, Cambridge University Press, Cambridge, UK, 2013.

[8] A. Kreinin, D. Novitski, and A. Weizman, "Amisulpride treatment of clozapine-induced hypersalivation in schizophrenia patients: a randomized, double-blind, placebo-controlled crossover study," International Clinical Psychopharmacology, vol. 21, no. 2, pp. 99-103, 2006.

[9] H. Schoemaker, Y. Claustre, D. Fage et al., "Neurochemical characteristics of amisulpride, an atypical dopamine D2/D3 receptor antagonist with both presynaptic and limbic selectivity," Journal of Pharmacology and Experimental Therapeutics, vol. 280, no. 1, pp. 83-97, 1997.

[10] T. Godoy, A. Riva, and J. Ekström, "Atypical antipsychoticseffects of amisulpride on salivary secretion and on clozapineinduced sialorrhea," Oral Diseases, vol. 18, no. 7, pp. 680-691, 2012. 


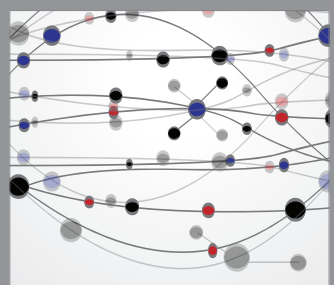

The Scientific World Journal
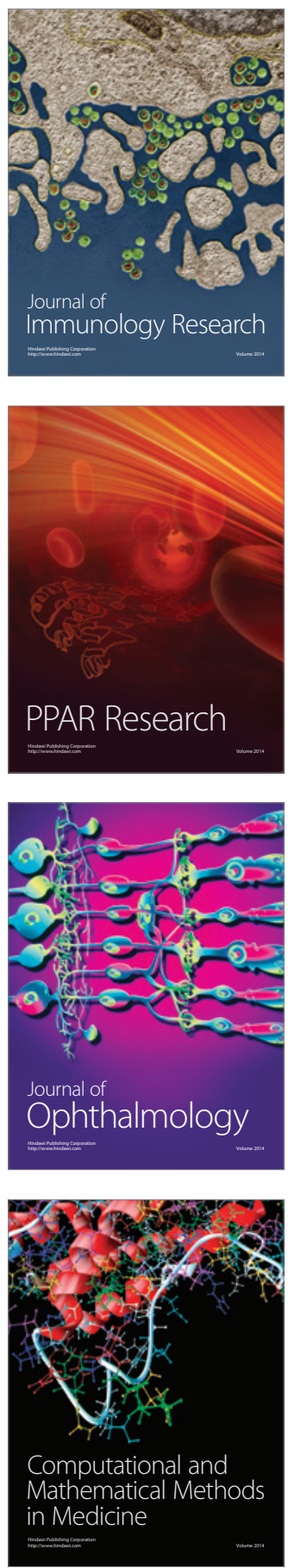

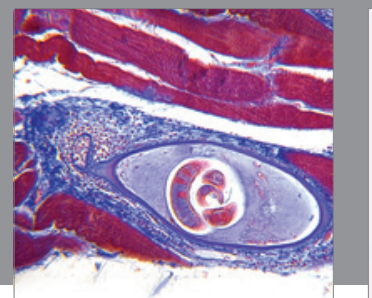

Gastroenterology

Research and Practice
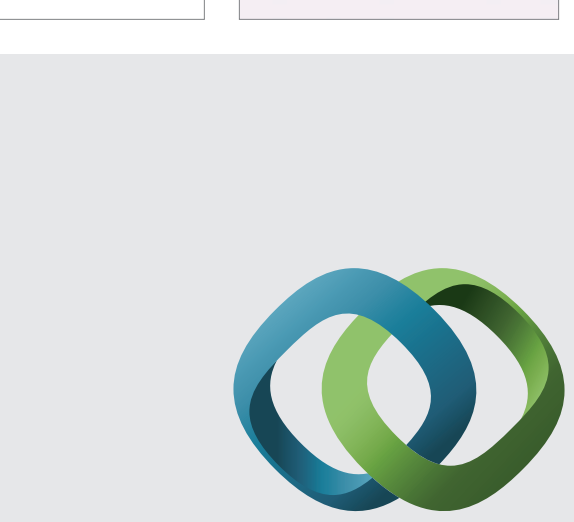

\section{Hindawi}

Submit your manuscripts at

http://www.hindawi.com
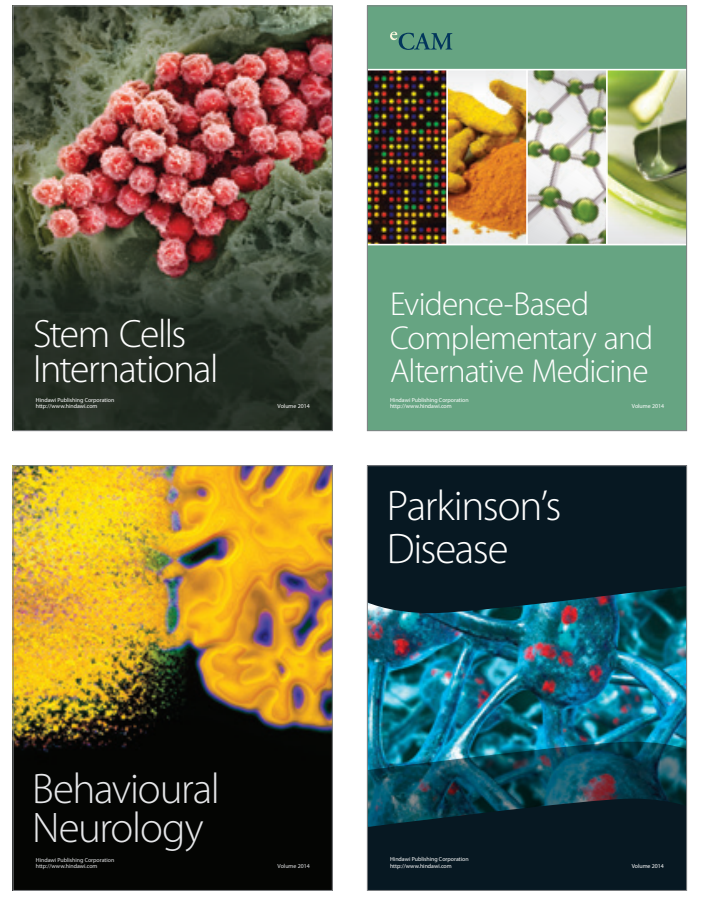
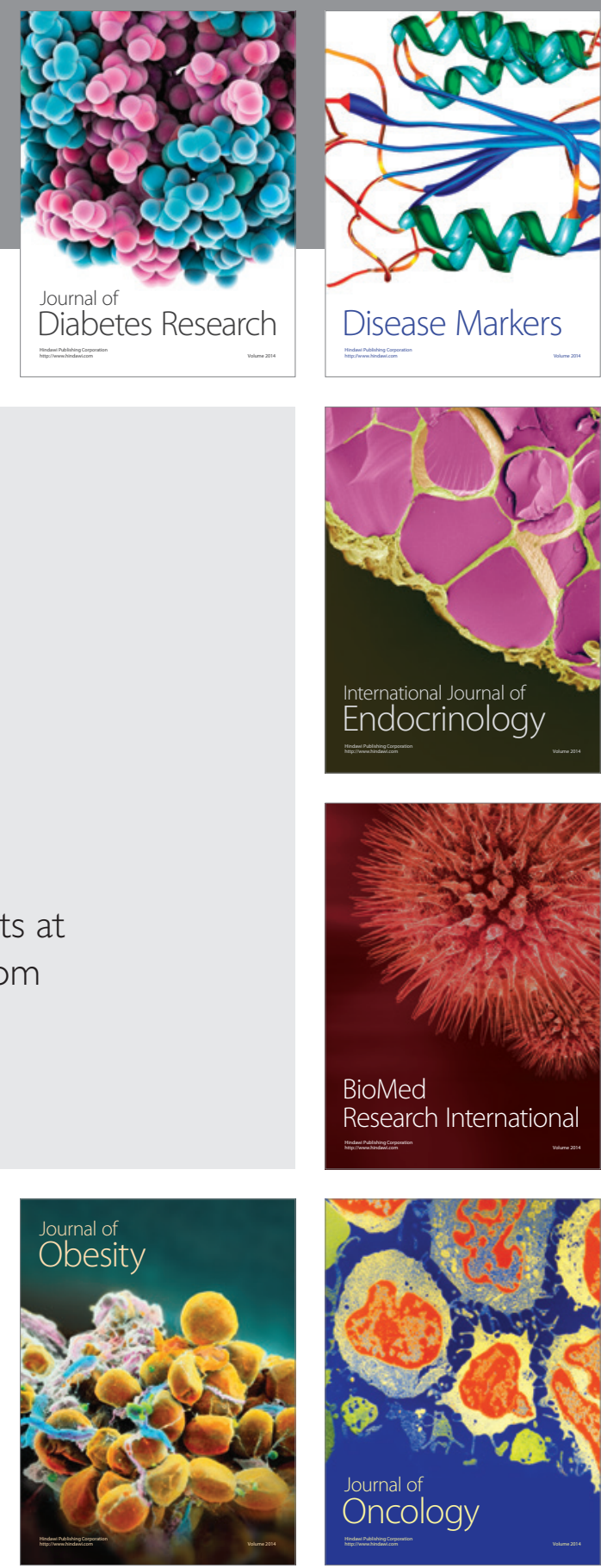

Disease Markers
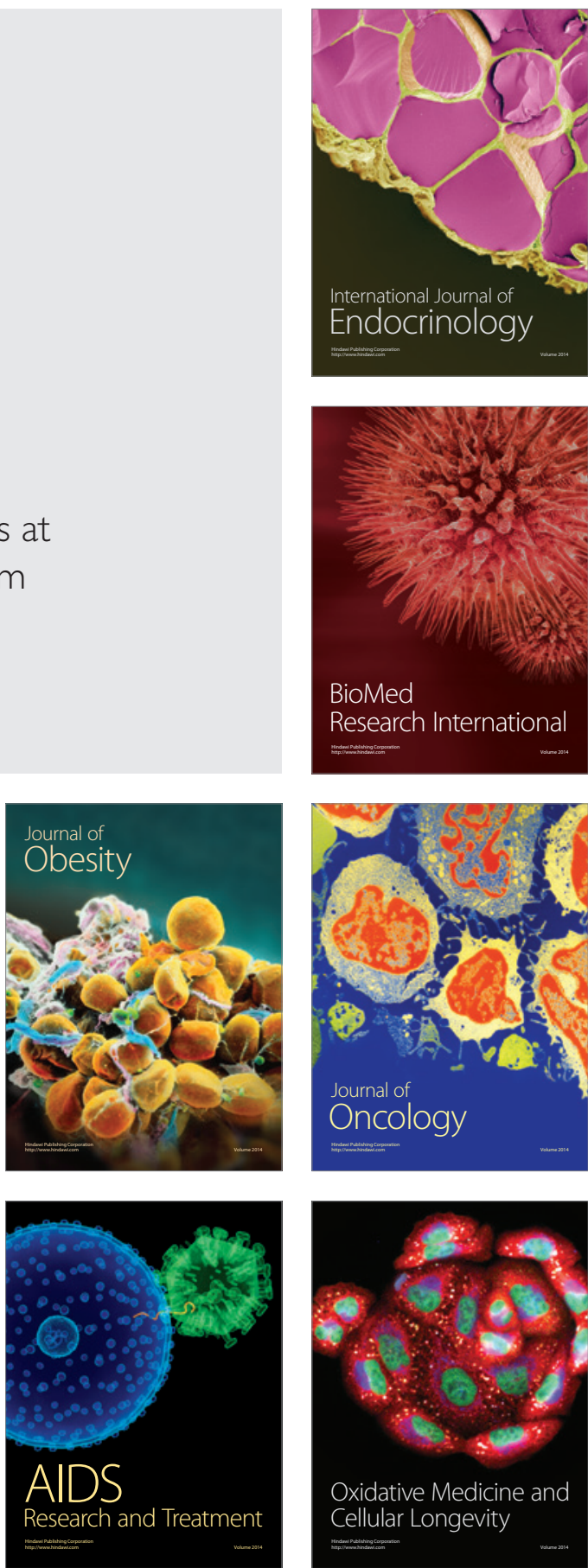